\title{
«MEZCLAR VERDADES CON FABULOSOS INTENTOS»: METATEATRO Y APORÍA EN EL GALLARDO ESPAÑOL DE CERVANTES
}

LOURDES ALBUISECH Southern Illinois University

Conocida es de todos la afición de Cervantes por el teatro. En el «prólogo al lector» de sus Ocho comedias y ocho entremeses nuevos, nunca representados, recuerda casi con nostalgia sus tempranos escarceos en el teatro, y se jacta de haber visto representar al gran Lope de Rueda. En el mismo lugar, menciona otras figuras del teatro español, pasadas y contemporáneas suyas, como Navarro, el «doctor Ramón», Miguel Sánchez, Mira de Amescua, Tárrega, Guillén de Castro, Gaspar de Aguilar, Luis Vélez de Guevara, Antonio de Galarza, Gaspar de Ávila y, claro, Lope de Vega. Cervantes sintió inevitablemente admiración y rencor hacia el Fénix. Referencias a los aciertos, pero también a las fallas, de la fórmula lopesca de la comedia nueva, abundan en las páginas cervantinas $^{1}$. Y es que, cuando Cervantes decidió volver al cultivo del teatro, ya corría el rumor, como hizo saber un autor de título al librero que compró la obra dramática de Cervantes, de que de la prosa cervantina «se podía esperar mucho, pero que del verso nada». Con toda probabilidad y a pesar de que afirma en su prólogo estar componiendo una comedia titulada El engaño a los ojos, Cervantes no escribió otras obras dramáticas después de la publicación de este tomo (1615) y, sin embargo, no dejamos de hallar hasta en su último escrito en prosa, el Persiles, diversos episodios

\footnotetext{
${ }^{1}$ Cervantes no dejó una obra de crítica o teoría dramática, aunque trató el tema en el Quijote I, 48, en la segunda jornada de El rufián dichoso y en el prólogo a su volumen teatral. Como señaló H. J. Chaytor, mientras que en El rufián dichoso, la figura de la Comedia justifica ante la Curiosidad los principios del teatro fijados por Lope, en el Quijote, el canónigo de Toledo y el cura parecen condenarlos.
}

AC, XXXVI (2004), 329-344 
y elementos teatrales. Es evidente que Cervantes mismo estaba poco convencido de la mala calidad de su dramaturgia de segunda hornada, si bien su prólogo rezuma desencanto ${ }^{2}$. Pocos han tomado en serio la instancia de Cervantes al lector, al final de su prólogo, a buscar «alguna cosa buena» en sus piezas teatrales ${ }^{3}$, con que poder rebatir al maldiciente autor. El propósito de nuestro estudio es precisamente aceptar el convite cervantino y analizar una de las "cosas buenas» que encierra una de sus producciones dramáticas, el elemento metateatral. Veremos además cómo los recursos metadramáticos, que realzan formalmente la idea del mundo como teatro, como juego o como engaño, como texto cuyos signos pueden reinventarse ad infinitum, sirven en El gallardo español para exponer los límites de la verdad, a través de temas o conceptos como el de valor.

Lionel Abel acuñó el término 'metateatro' stricto sensu ${ }^{4}$ para referirse a un grupo de obras cuya antigüedad se remonta al menos al teatro inglés elisabetiano. Abel contrapuso metadrama a tragedia o, como él mismo explica, un conjunto de piezas teatrales autorreflexivas a un grupo de obras que se vale del concepto de hybris del que carece el pensamiento occidental moderno. Debido a que, como señaló Susan Sontag en su excelente comentario sobre el libro ya clásico de Lionel Abel, éste no se ocupa de la comedia, numerosos críticos se han planteado si el marbete podría igualmente aplicarse a la comedia nueva española ${ }^{5}$. El objeti-

\footnotetext{
${ }^{2}$ Sigo la edición de Florencio Sevilla Arroyo y Antonio Rey Hazas del Teatro completo de Cervantes. Las citas extraídas de los textos preliminares van seguidas del número de página. En cambio, las citas sacadas de El gallardo español se refieren al número de los versos. En el prólogo, Cervantes afirma claramente la validez de sus textos dramáticos: "Torné a pasar los ojos por mis comedias y por algunos entremeses míos que con ellas estaban arrinconados, y vi no ser tan malas ni tan malos que no mereciesen salir de las tinieblas del ingenio de aquel autor a la luz de otros autores menos escrupulosos y más entendidos» (12). De nuevo, en la dedicatoria al Conde de Lemos, Cervantes insiste: «[...] V.E., a quien ofrezco el destas comedias y entremeses, no tan desabridos, a mi parecer, que no puedan dar algún gusto» (13). Edward Friedman asegura que aunque el rechazo "left Cervantes embittered over the state of the theater, it seems evident from his references to drama that he believed in the intrinsic quality of his plays» (2).

${ }^{3}$ "Querrían que fuesen las mejores del mundo, o, a lo menos, razonables; tú lo verás, lector mío, y si hallares que tienen alguna cosa buena, en topando a aquel mi maldiciente autor, dile que se emiende [...]» (Cervantes, 12).

${ }^{4}$ Uso el término en el sentido que lo usó Claudio Guillén en Literature as System en relación a la narrativa picaresca. Guillén hablaba de picaresca stricto sensu (que coincide con el "género histórico» de Todorov), picaresca sensu lato (similar al "género teórico todoroviano) y de "gusto picaresco».

${ }^{5}$ LIONEL ABEL, Metatheatre: A New View of Dramatic Form, New York: Hill and Wang, 1963. Abel dedica considerable espacio al comentario de Hamlet, pero se refiere a algunas obras españolas, como La vida es sueño de Calderón y Don
} 
vo del metadrama es jugar con la ilusión dramática, acentuando así los conceptos de theatrum mundi o de la vida como sueño ${ }^{6}$. Richard Hornby coincide con Abel al afirmar que "Briefly, metadrama can be defined as drama about drama; it occurs whenever the subject of a play turns out to be, in some sense, drama itself» (31). Sin embargo, para Hornby, el carácter reflexible y autorreflexivo (autotélico) de toda obra dramática confieren a ésta, sensu lato, un carácter metadramático. Se trata, por tanto, de un fenómeno transhistórico. Lo que varía es el tipo de recurso metadramático así como el grado en que lo metateatral es empleado conscientemente. Hornby clasifica las variedades de lo metadramático en: teatro dentro del teatro, ceremonia dentro del teatro, representación de un papel dentro de otro papel, referencias literarias (intertextualidad) y a la vida real, autorreferencia (intratextualidad) y análisis de la percepción. Algunos de estos recursos proliferan en ciertos períodos y escasean en otros. Así, el teatro dentro del teatro es explotado, de acuerdo a Hornby, en épocas como el siglo XVII, caracterizadas por un exacerbado cinismo de la sociedad sobre la vida. Precisamente y como explica Emilio Orozco Díaz, el Barroco engendró un gran teatro por ser una época en que el hombre pierde la fe en sí mismo, en la naturaleza y en la realidad que le rodea y priva al mundo de todo valor (238-39). Es por ello que, durante el Barroco, se erige el teatro como el género de masas (Orozco 147) y todo en la vida y en el arte mismo se teatraliza. Dentro del teatro, tal teatralización se descubre en el desbordamiento de recursos teatrales así como en la incorporación del teatro como tema al hecho de la ficción dramática (Orozco 240-41). Mediante el empleo de metateatro el dramaturgo puede dejar al descubierto la máquina fabulosa del teatro, exponer su artificiosidad, hacer que el público cuestione la 'realidad' de la acción teatral (produciendo así una dislocación perceptiva o un distanciamiento) o perciba la teatralidad del mundo. Cabe recordar, en este sentido, la influencia que ejercieron las

Quijote de Cervantes, igualmente como obras metadramáticas (ver especialmente págs. 64-72). La cuestión de la metateatralidad de la comedia nueva se debatió durante la década de los 70 (en varios artículos de Thomas O'Connor, Stephen Lipmann y Frank P. Casa, entre otros). Posteriormente, muchos textos teatrales han sido analizados como metateatro, y algunos estudiosos como Catherine Larson han postulado las posibilidades que dicho tipo de análisis ofrece aún hoy para los investigadores.

${ }^{6}$ Susan Sontag reconocía como el mayor mérito abeliano el haber tratado el tema de la muerte de la tragedia objetivamente, si bien apuntaba tres fallos en la obra de Abel, a saber: el ignorar la comedia, el pasar por alto el hecho de que en un mundo cristiano era imposible que se diera la tragedia y el considerar indiscriminadamente el teatro didáctico brechtiano como metateatro. 
definiciones de comedia que dieron Cicerón y Livio Andrónico - la comedia como espejo de la vida- en la literatura de la Edad de Oro y en Cervantes en particular ${ }^{7}$.

Todo estudio en torno al aspecto reflexivo en la producción cervantina debe partir necesariamente del Quijote ya que, como reparara Abel, «Don Quixote, though he appears in a novel - the novel of an ex-playwright - projects in the most complete and perfect way the dramatic horizon of all plays about self-referring characters» $(65)^{8}$. Es, entre otras cosas, ese aspecto autoconsciente del gran pluscuamlibro (como lo tildó Luis Andrés Murillo) lo que hizo posible la reconstrucción de una "teoría de la novela» cervantina a E.C. Riley. Sin embargo, conviene analizar el elemento reflexible en el resto del corpus del alcalaíno. El mismo Abel, a quien se debe la sagaz observación de que "Reflection was something natural to Cervantes» (65), no se detuvo a comentar otras obras cervantinas. Entremeses como El retablo de las maravillas o La cueva de Salamanca, quizá por el hecho evidente de que cualquier entremés constituye, de entrada, teatro dentro del teatro, han sido objeto de numerosos estudios desde el punto de vista metadramático. Patricia Kenworthy señaló que "Si el Quijote es, en cierto sentido, una novela sobre cómo escribir una novela, los entremeses pueden ser considerados como piezas dramáticas que dramatizan la creación del ilusionismo» (235) ${ }^{9}$. Asimismo, recientemente Carlos Arturo Arboleda elaboró una teoría del metateatro en Cervantes, en cuya obra aprecia un sobreinflujo de técnicas de la commedia dell'arte italiana como la improvisación, que eleva al puesto de nueva categoría metadramática (aparte de las catalogadas por Hornby).

Desafortunadamente, el aspecto metadramático en las comedias cervantinas ${ }^{10}$ no ha sido estudiado en profundidad. Para Edward Friedman, como para Joaquín Casalduero, Cervantes es claramente un autor del primer barroco, frente a Lope de Vega, representante del segundo barroco. Los dramas creados por Cervantes, fustigados ad nauseam a través de siglos, carecen de la unidad de acción aparente en la comedia nueva de Lope y sus défenseurs y se caracterizan, en cambio, por una unidad conceptual. Si bien las comedias escritas por Cervantes en un primer

\footnotetext{
${ }^{7}$ Véase Margarete Newels (80-82). Genre.

${ }^{8}$ Véase también Robert Alter, Partial Magic: The Novel as a Self-Conscious

${ }^{9}$ Pueden consultarse, además del trabajo de Patricia Kenworthy, Rosa Rossi, Dawn Smith y Carlos Arturo Arboleda (especialmente, pp. 42-44).

${ }_{10} \mathrm{Ni}$ siquiera Carlos Arturo Arboleda se ocupa de ellas. Su estudio se enfoca, principalmente, en los entremeses.
} 
período (aproximadamente hasta 1582) fueron bienquistas por el público, una vez triunfó la comedia lopesca, sorda a la preceptiva neoaristotélica y complaciente con el vulgo, la fórmula cervantina iba forzosamente a fracasar. Es por ello que, como indica Friedman (y anuncia la Comedia en El rufián dichoso), cuando Cervantes vuelve a escribir para las tablas (alrededor de 1592) debe claudicar al nuevo uso ${ }^{11}$.

Friedman dedica un capítulo al tema del mundo como teatro en El laberinto de amor y en La entretenida, y comenta asimismo la confusión de ficción y realidad que se da en obras como $\mathrm{La}$ Numancia, en que los numantinos dramatizan su destino histórico. En las obras de cautiverio advierte Friedman una mayor separación entre historia y ficción, si bien la poca libertad que gozan los cautivos históricamente hablando, se ve compensada por su autonomía en el plano ficcional o poético.

En El Gallardo español Guzmán apunta a dicho emborronamiento de fronteras entre historia y ficción al afirmar que el propósito principal de la obra «ha sido mezclar verdades / con fabulosos intentos» (vv. 3133-3134) ${ }^{12}$. En efecto, en 1563 los españoles hubieron de resistir el cerco procurado por Hascén Bajá sobre las plazas de Mazalquivir y Orán. Figuras como don Alonso Fernández de Córdoba, segundo conde de Alcaudete, Fratín, apodo del ingeniero italiano Giacome Paleazzo, don Martín de Córdoba, hermano de don Alonso, Hascén Bajá (Azán), director de la campaña bélica, don Fernando de Cárcamo, don Francisco de Mendoza, hermano de don Juan de Mendoza, y don Alvaro Bazán, son históricas. La alegación didascálica "Y esto de pedir para las ánimas es cuento verdadero, que yo lo vi» (34), redunda en la verosimilitud de lo representado, una de las preocupaciones más acuciantes

11 Según Michel Darbord, "Cervantes admet encore dans le Rufián dichoso, une des huit comedias de 1615, que l'on se résigne à suivre la mode qui change toutes choses, mais il ne faut pas s'y tromper. Au fond, il est resté fidèle à ses idées» (21). Puede leerse algo similar en Ángel VAlBuEna PRAT, El teatro español en su siglo de Oro (11).

12 Angel Valbuena Prat señaló que donde el texto cervantino dice «intentos», debe leerse «inventos» (21). De no ser una errata, "intentos» sería sinónimo de 'intenciones', 'propósitos,' y haría alusión a las 'intenciones' más fabulosas de la obra: la de Arlaxa y Alimuzel de capturar vivo a don Fernando, por un lado, y la de Margarita de encontrar al mismo don Fernando (aunque por motivos y con una finalidad bien distintos), por otro. Para Kartchner, se refiere a las intenciones nunca del todo claras de cada personaje (27-35). "Inventos» aludiría al carácter ficticio de parte de los acontecimientos que constituyen la narratio dramatica (precisamente todo lo relacionado con las intrigas amorosas - así entre moros como entre cristianos - y con el capricho de Arlaxa). En lo esencial, entonces, 'intentos' o 'inventos' se refiere a lo mismo. Nosotros vamos a respetar la ortografía cervantina. 
del canónigo de Toledo en torno a la comedia nueva (Quijote I, 48). Cervantes viajó a Orán en 1581 y, como señala Angel Valbuena Prat, no ha faltado quien haya sugerido que el personaje central de la comedia, don Fernando de Saavedra, comparte más que el apellido con su creador (21). La incursión de lo histórico en lo poético (ficticio) confieren al plano poético un aura de historicidad, un grano de credibilidad $^{13}$, y constituyen, además, ejemplos de referencias a la vida real que, reconocidas por algún espectador o lector, pueden producir un efecto metadramático (si bien es casi seguro que la celebridad de El gallardo español se debe más al ingrediente novelesco que al histórico [Valbuena Prat 22-23]).

Aparte de funcionar como deixis del hibridismo de la acción dramática, «mezclar verdades con fabulosos intentos» apunta también a lo que Eric Kartchner considera como el tema más destacado en la obra: la dicotomía entre verdad y ficción ${ }^{14}$. Este tema, que Kartchner estudia en relación a la ambigüedad en las intenciones de los personajes, está íntimamente ligado, en mi opinión, al concepto de la gallardía (o la falta de ella), ya manifiesto desde el título de la comedia. Vocablos como 'gallardo', 'valor', 'valiente', 'bravo', brío', 'cobarde', 'miedo', 'temor', etc., abundan en los tres actos, aplicados a diversas situaciones y personajes. Trama y subtrama presentan notables paralelismos argumentales: ambas se articulan en torno a la atracción que una mujer (Arlaxa en la trama, Margarita en la subtrama) siente por la idea que se ha formado sobre don Fernando a partir de los comentarios favorables que sobre sus hazañas y su valor han proferido otros (Oropesa y Vozmediano respectivamente). Las diferencias entre trama y subtrama estriban, principalmente, en la decisión que cada una de las mujeres adopta en relación a la negociación de dicha atracción y en los medios de que se vale cada una para consolidar su decisión. El fin de la mora es ver a don Fernando doblegado a sus pies; el medio de llevar esto a cabo es enviando a Alimuzel, uno de sus pretendientes, a Orán a capturar al cristiano. El propósito de Margarita es casarse con don Fernando, para lo cual debe partir en su busca, primero a Italia y luego a Orán.

13 Joaquín Casalduero (54-55), Florencio Sevilla Arroyo y Antonio Rey Hazas (15) y Edward Friedman (29) han subrayado la importancia del enunciado que cierra la obra en tanto que hace referencia a la confusión entre historia (verdad) y ficción (mentira), pero no han reparado en el mismo como recurso metadramático. Frederick A. De Armas rebatió la tesis de que El gallardo español tiene una estructura desmañada. Para él, el tema central es la relación armoniosa de contrarios (Venus y Marte).

${ }^{14}$ Aparte de Kartchner, resulta de sumo interés el artículo de Michael Gerli sobre la manera en que Cervantes subvierte el concepto de verosimilitud aristotélica. 
Aunque algunos personajes (Oropesa, Vozmediano, Guzmán) creen, en virtud de lo que han visto, en la gallardía del soldado cristiano Saavedra, es el cuestionamiento o la duda sobre dicha valentía lo que pone en marcha la acción. Arlaxa quiere comprobar por sí misma si la fama del cristiano está bien o mal fundada. Si Alimuzel consigue acometer con éxito el encargo, la fama del vencido pasará al vencedor, como recuerda Oropesa (738-39). $\mathrm{Si}$, por el contrario, es Saavedra quien vence, Arlaxa nunca lo verá, y su deseo quedará insatisfecho. La empresa entraña así la posibilidad de que don Fernando no sea tan brioso como la fama proclama. Esto mismo es sugerido por Alimuzel en su discurso de desafío. Al llegar a Orán, el moro provoca a don Fernando de la siguiente manera (203-218):

$$
\begin{aligned}
& \text { Y para darte ocasión } \\
& \text { de que salgas mano a mano } \\
& \text { a verte conmigo agora, } \\
& \text { destas cosas te hago cargo: } \\
& \text { que peleas desde lejos, } \\
& \text { que el arcabuz es tu amparo, } \\
& \text { que en comunidad aguijas } \\
& \text { y a solas te vas de espacio; } \\
& \text { que eres Ulises nocturno, } \\
& \text { no Telamón al sol claro; } \\
& \text { que nunca mides tu espada } \\
& \text { con otra, a fuer de hidalgo. } \\
& \text { Si no sales, verdad digo; } \\
& \text { si sales, quedará llano, } \\
& \text { ya vencido o vencedor, } \\
& \text { que tu fama no habla en vano. }
\end{aligned}
$$

Al aguijar así públicamente su honor y su orgullo, don Fernando va a desobedecer las órdenes del general don Alonso, que le insta a permanecer en Orán ante el inminente cerco turco, y va a entregarse a los moros bajo el nombre apócrifo de Juan Lozano. Los términos 'gallardo' y 'cobarde' se muestran, además, polisémicos. "Gallardas» son tanto las acciones que revisten esfuerzo en su acometimiento (así la victoria de don Fernando sobre el bajel turco, narrada por Oropesa entre los versos 1146 y 1192, o el ofrecimiento de las mujeres españolas de permanecer en Orán durante el cerco), como otras que no entrañan arrojo de ningún tipo (Buitrago, por ejemplo, califica de «bravo» a don Martín cuando éste le da limosna y le asegura que lo llevará con él a Mazalquivir [689] y, cuando Guzmán lo convida, no tiene empacho en compararlo con Alejandro y con Marte [1515]). "Cobarde» es tanto el pusilánime Nacor, como el valiente Alimuzel, que en su galopar presuroso hacia Orán, «mira a todas partes, recatado, como quien 
miedo y osadía tiene» (138-39), y durante el saco del aduar huye de Buitrago. El propio don Fernando subvierte su supuesta gallardía al describir la rendición del joven soldado (en realidad, Margarita) al enemigo como un acto cobarde (1990), pese a que él ha hecho lo mismo. Así, lejos de oponerse, el concepto de gallardía engloba y es englobado por el de cobardía.

La gallardía del español no es lo único que queda en entredicho. Su desaparición del frente cristiano cuando más se precisa de él, hace cuestionar a muchos su cristiandad. La apostasía es sugerida en primer lugar por el alférez Robledo, que se gana por ello la enemistad de Guzmán. Cuando Margarita llega a Orán, el rumor de que don Fernando ha renegado es pregonado hasta por los niños (1281-82). Los motivos que inducen a don Fernando a pelear contra los cristianos en la escena del saqueo del aduar son ambiguos, y hacen dudar al mismísimo Oropesa: «O está don Fernando loco, / o es ya de Cristo enemigo» (1641-42). El gracioso Buitrago expresa una opinión paralela: «¡Oh Robledo / verdadero y memorando, / y cuánta verdad dijiste!» (1825-27), y la defensa que de su amigo hace Guzmán, provoca el comentario sarcástico de don Martín: «Por cierto, oh buen Guzmán, que estáis donoso! / Pues ¿cómo no se ha vuelto, o cómo muestra / contra cristianos ánimo brioso?»(1951-53).

¿Cuál es la verdad sobre su gallardía y sobre su fe religiosa? La naturaleza polisémica y ambagiosa del lenguaje, la ausencia de claridad en la exposición de motivos y los diferentes puntos de vista dificultan de manera prodigiosa el discernimiento a tal cuestión ${ }^{15}$. Como dice Kartchner "The search for the truth in the web of fictions becomes the objective of the characters and of the reader/ spectator, but, as in real life, the truth is not easily recreated» (34). Irónicamente, para buscar la verdad, los personajes recurren a la mentira y al engaño. Como cautivo voluntario, don Fernando dirá llamarse Juan Lozano, y haberse entregado "por no poder tolerar / ser valiente y mal pagado» (823-824). El jerife Nacor aconseja a Alimuzel que se retire de Orán y que regrese junto a Arlaxa a esperar mejor ocasión para capturar a don Fernando, asegurándole que lo defenderá ante Arlaxa: «Ven, que a Arlaxa daré cuenta / de modo que diga y sienta / que eres vencedor osado" (512514). Sin embargo, una vez frente a Arlaxa, Nacor acusa a Alimuzel de cobarde. Cuando Nacor se presenta ante Arlaxa para despedirse, la mora reconoce ante don Fernando y Oropesa que «Aqueste Nacor me enfada» (1210), pero enseguida, por recomen-

${ }^{15}$ Sobre el multiperspectivismo en la obra, puede consultarse el artículo de William A. Stapp. 
dación de éstos, finge alegrarse de verle: «Buen suceso / y agüero espero y te doy, / porque irás en gracia mía, / y en verte tomó alegría / desusada el corazón»(1218-1222). El propio Oropesa comentará refiriéndose a Arlaxa: "Ella es falsa cuanto es bella» (1259). Margarita, acude primero a Italia y a Orán en hábito de hombre y después fingirá ante su hermano ser la mora Fátima, hermana de Arlaxa. También Vozmediano miente: primero al conde sobre los motivos de su venida a Orán junto con el joven galán jerezano (Margarita), y después a don Juan asegurando que su nombre es Pedro Álvarez.

Exceptuando el ejemplo de mentira oficiosa que ofrece el comportamiento de Arlaxa, y cuyo efecto en el público no es de distanciamiento, el resto de las situaciones citadas constituyen claramente muestras de representación de un papel dentro de otro. Este recurso metadramático funciona como medio para delinear al personaje y sirve para exponer la naturaleza misma de la representación de papeles (Hornby 67-73). Su uso recuerda, según Hornby, la relatividad de los roles humanos y la calidad aprehensible de la identidad (72), pero también sirve para subrayar "the differences between the sexes, since women must resort to using role-playing and other theatrical devices in order to achieve some measure of power or authority" (Larson 213) ${ }^{16}$.

Tanto don Fernando al personificar a Juan Lozano, como Margarita y Vozmediano al hacerse pasar, ella, por soldado y por mora, y él, por Pedro Álvarez, actúan voluntariamente ante un nuevo público que surge inesperadamente en escena, como reflejo microcósmico del público real que, sentado o de pie, asiste a la representación de una representación. La imposición voluntaria de un papel conlleva, además, a la improvisación por parte de los actores noveles. Ni Margarita vestida de mora, ni don Fernando vestido de moro, ni Vozmediano, capturado por los moros, esperan la llegada de don Juan, hermano de Margarita. Su aparición como cautivo pone en marcha el mecanismo de la improvisación. Una situación semejante se da al descubrir Alimuzel al jerife Nacor ante sí al pie de la muralla oranesa. Mientras contempla a Alimuzel dormido, el cobarde jerife expresa su deseo de matarle. Sin embargo, el improviso despertar de Alimuzel le obliga a actuar rápidamente concibiendo un plan engañoso.

${ }^{16}$ Recientemente, Christopher Weimer ha interpretado los cambios de papel en otra comedia cervantina de tema oriental, La gran sultana, como ejemplos de castración en el sentido lacaniano y barthiano. Me parece que su definición de castración como "the literal, symbolic, or figurative dissociation of individuals from a fundamental sense of self or self-definition" (52) podría muy bien aplicarse a otras instancias de travestismo en el drama aurisecular, incluido El gallardo español. 
Dentro de la obra, los públicos y sus reacciones a cada una de las actuaciones de don Fernando, Margarita y Vozmediano van a ser múltiples, replicando de este modo los variables niveles interactivos de los públicos verdaderos con el hecho representado. En la obra, algunos espectadores ni siquiera se dan cuenta del artificio que se despliega ante sus ojos: los moros no son conscientes del engaño de don Fernando, como tampoco lo son los cristianos (incluyendo a don Fernando) del de Margarita al aparecer travestida. Otro tipo de espectadores, en cambio, detectan dichos engaños: Oropesa advierte quién es realmente Juan Lozano ${ }^{17}$ y don Juan de Valderrama, el hermano de Margarita, cuestiona asimismo la identidad de Juan Lozano, la de Fátima y la de Pedro Álvarez. Indirectamente, el dramaturgo está examinando así la manera en que la sociedad puede percibir la realidad.

La percepción como tema dramatizado constituye según Hornby otra variedad de lo metadramático. Como ya señalara Friedman, la mudanza de papeles por parte de don Fernando y de Margarita es parcialmente impulsada por la esperanza de afirmar su autenticidad como individuos (30). Don Fernando se percibe como verdaderamente gallardo; de ahí que asuma el nombre espurio de Juan Lozano, un sinónimo de 'gallardo.' Margarita, a su vez, funda su existencia en el deseo de esposarse con el hombre de quien dice haberse enamorado de oídas, don Fernando de Saavedra. El momento climático respecto a la problematización de la percepción lo constituye, sin duda, el triple reencuentro entre don Juan de Valderrama, hermano de Margarita, y don Fernando, Margarita y Vozmediano. Al ver a don Fernando, don Juan se pregunta "¿Qué es lo que veo, Cielos soberanos?»(2477). Una vez que se quedan solos, don Fernando, que va vestido de moro, le pide que espere; don Juan contesta, en un aparte: "Ya espero, ya escucho, y veo / lo que nunca ver quisiera, / si me pinta aquí el deseo / esta visión verdadera»(2529-2532) y, poco después murmura: «... pienso que estoy mirando / el rostro de don Fernando, / su habla, su talle y brío; / pero que esto es desvarío / su traje me va mostrando» (2543-2547) y "porque tanto te pareces / a un cristiano, que me admiro, / que le veo si te miro, / y él mismo en ti mismo ofreces» (2554-2557). Don Fernando explica que tiene un doble cristiano en Orán. Al final de la conversación, don Juan aún duda: "mas, con todo aquesto, creo... / Pero no, no creo nada; / que es cosa desvariada / dar crédito a lo que veo» (2584-2587). Una

${ }^{17}$ En el aduar de Arlaxa, el único personaje que reconoce a don Fernando en Juan Lozano es el cautivo cristiano Oropesa, a quien don Fernando instruye para que guarde el secreto. 
vez solo, don Fernando reconoce que «Entre sospechas y antojos, / y en gran confusión metido, / va don Juan lleno de enojos, / pues le estorba este vestido / no dar crédito a sus ojos. / No se puede persuadir / que yo pudiese venir ! a ser moro y renegar, / y así, se deja llevar / de lo que quise fingir» (2588-2597).

La percepción a través de la vista es engañosa, pero también lo es la percepción a través del oído. La voz de la mora Fátima - realmente Margarita - enciende en don Juan el deseo de que se descubra el rostro: "Ayer me entró por la vista / cruda rabia a los sentidos, / y hoy me entra por los oídos, / sin haber quien la resista. / Ayer la suerte inhumana, / a quien mil veces maldigo, / me hizo ver mi enemigo, / y hoy me hace oír mi hermana» (26402647). Arlaxa, que actúa como "metaautora de comedias» en esta instancia, pide a «Fátima» que se descubra $\mathrm{y}$, en un aparte, tranquiliza a la cristiana diciendo que aunque su hermano la reconozca, sólo tiene que negar su identidad. Al final de la escena, tras ver el rostro de Margarita, don Juan está seguro de que la mora Fátima es su hermana, si bien expresa en un breve soliloquio su confusión: «Extraño es el devaneo / con quien vengo a contender, / pues no me deja creer / lo que con los ojos veo" (2736-2739). Así las cosas, Vozmediano es capturado. Al verle, don Juan se dice: "Si aquéste no es Vozmediano, / concluyo con que estoy loco» (2890-2891). De ahí la desesperación de don Juan cuando Vozmediano asegura ser Pedro Álvarez.

Cuando un drama, que es a fin de cuentas un medio de percepción, se enfoca en la percepción, se hace reversible, se vuelve sobre sí mismo hasta mostrarnos sus forros más recónditos, o mostrársenos del todo desnudo. El engaño a los ojos de don Juan evoca el engaño a los ojos del público que asiste a la representación teatral. Cuando don Fernando, Margarita y Vozmediano se hacen pasar por Juan Lozano, Fátima y Pedro Alvarez, respectivamente, se convierten en actores. Don Juan y otros personajes de la obra ante quienes actúan, se convierten en su público. Estas dramatizaciones se hacen eco del hecho teatral mismo, donde los cómicos representan su papel ante un público que los contempla ir y venir sobre el tablado. Así como la confusión de don Juan se disipa al concluir la obra con la confesión de don Fernando (3043-3066), la ilusión presentada temporalmente al lector/espectador se desvanece al tocar El gallardo español a su fin.

El teatro es metáfora de la vida. Si el público es capaz de reconocer este aspecto a la par que observa frente a sí el desenvolvimiento de la acción dramática, se producirá un extrañamiento metadramático. Algo similar ocurre en relación a otra de las variedades de metateatro consideradas por Hornby, la intertextua- 
lidad. Cuando el público reconoce como tal una alusión literaria, el grado de distanciamiento metadramático se ve incrementado. A Florencio Sevilla Arroyo y a Antonio Rey Hazas dos acontecimientos de El gallardo español les recordaron a una obra anterior de Cervantes, La Numancia. Me refiero, en primer lugar, a la reacción del general de Orán, don Alonso de Córdoba, ante la llegada de Alimuzel: "Si es embajada, yo le doy seguro» (145), que recuerda a ambos estudiosos a «la actitud de Cipión ante la primera embajada numantina» (21). En segundo lugar, me refiero a la petición de Isabel de Avellaneda en nombre del colectivo de las mujeres de obtener permiso para permanecer en Orán durante el cerco turco para ayudar a los hombres y morir con ellos si es preciso (569-607). Esta petición se hace eco de los argumentos usados por las mujeres numantinas para seguir el mismo destino que los hombres. En ambos casos, sin embargo, el efecto de distanciamiento depende del grado en que el lector/espectador evoque a su vez La Numancia al leer/escuchar estos pasajes de El gallardo español ${ }^{18}$.

Algo distinto ocurre con el único ejemplo de autorreferencialidad que hallamos en El gallardo español. Se trata del cierre mismo de la obra, al que ya nos hemos referido anteriormente, cuando Guzmán pide al soldado comilón, Buitrago, que «no haya más, que llega el tiempo / de dar fin a esta comedia, / cuyo principal intento / ha sido mezclar verdades / con fabulosos intentos» (3130-3134). Este tipo de final, en que un personaje o varios se despiden del público, es convencional en la comedia. Tales despedidas constituyen siempre exponentes de lo metadramático, ya que llaman la atención sobre la obra misma y desde dentro de la obra misma.

Cervantes mismo pone fin a varias de sus comedias recordando al público que es hora de terminar: En El rufián dichoso, el Virrey termina su parlamento diciendo que «aquí da fin felice esta comedia» (2846); Ocaña, en La entretenida, pide que le «den testimonio: / que acaba sin matrimonio / la comedia entretenida» (3085-3087); y Aurelio, en El Trato de Argel, hace gala de su modestia de la siguiente manera: "Y en tanto que llega el tiempo y

${ }^{18}$ Hornby advierte que «metadramatic literary references are direct, conscous [sic] allusions to specific works... that are recent and popular. The work or works referred to must not yet be part of the drama/culture complex but should preferably be avant-garde, or at least somewhat controversial» (90). La cita, la alegoría, la parodia y la adaptación son, en este sentido, ejemplos de referencias literarias metadramáticas. En El gallardo español sólo tenemos ecos de $\mathrm{La}$ Numancia. Ahora bien, el hecho de que los estudiosos hayan reparado en tales alusiones hace de $E l$ gallardo español una obra autorreferencial. 
punto / de poner en efecto mi deseo / al ilustre auditorio que está junto, / en quien tanta bondad discierno y veo, / si ha estado mal sacado este trasunto / de la vida de Argel y trato feo, / pues es bueno el deseo que ha tenido, / en nombre del autor, perdón $1[\mathrm{e}$ pido]» (2530-2537). Con todo, es el parlamento que cierra Los baños de Argel el que más recuerda al final de El gallardo español, ya que don Lope se refiere, entre los versos 3082 y 3093, a la consabida mezcla de "verdad e historia», a la par que se despide del público:

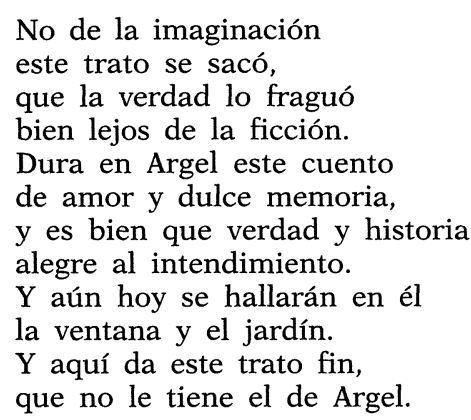

En el caso que nos ocupa, el personaje Guzmán se sale del marco de la obra para revelar al público que El gallardo español es una ficción imaginaria, una comedia. Con el reconocimiento por parte de los lectores (o espectadores) de que aquello que se ha estado leyendo (o viendo) es una ficción, ésta se desvanece de golpe. Tan sólo segundos antes de que la obra toque a su fin, se develan la ilusión y la ficción ${ }^{19}$ a través de un personaje que, como parte de ese mundo ilusorio y ficticio, lo deja atrás y adquiere un nuevo papel, el de comentador, que sabe cuál ha sido el propósito de la obra. "Mezclar verdades con fabulosos intentos» se refiere, entonces, a la mezcla de historia y ficción ${ }^{20}$, a la mascarada en que participan voluntariamente los personajes (y, por extensión, el mundo) y a la mistificación a que es capaz de someternos el

${ }^{19}$ Los terminos ilusión y ficción no son en modo alguno sinónimos. El hecho teatral es, en sí, una ilusión en tanto en cuanto constituye un engaño a los sentidos. En el caso de El gallardo español, la historia de don Fernando es, además, ficción puesto que se trata de una invención de Cervantes.

${ }^{20}$ Hay que añadir, todo sea dicho de paso, que esa mezcla de historia y fábula (en el sentido aurisecular de 'ficción') evidencia la naturaleza 'tragicómica' de la obra ya que, como estimaba un contemporáneo de Cervantes, ALONSO LóPEZ Pinciano, en su Philosophía antigua poética (1595), "La tragedia se funda en historia, y la comedia, es toda fabula, de manera que ni aun el nombre es lícito poner de persona alguna» (Newels, 71). 
teatro, haciendo pasar por verdad, aunque sólo sea temporalmente, aquello que es simplemente teatro, ilusionismo.

Cervantes crea con El gallardo español un drama autoconsciente, y exige del público que se entretenga, pero también que se dé cuenta de que lo que está apareciendo ante sus ojos no es más que una ilusión. Logra este segundo propósito valiéndose de un repertorio de recursos como las referencias a la vida real e intertextuales, la autorreferencialidad, la exploración del fenómeno de la percepción y la libertad otorgada a los personajes, que son capaces de reinventarse y de improvisar.

La común práctica cervantina de experimentar y de subvertir patrones genéricos se revela una vez más en El gallardo español. En la época en que escribe Cervantes, la teoría y la práctica exigían que la comedia comenzase con un conflicto cuya resolución se diera, felizmente, al final. No cabe duda de que El gallardo termina felizmente, con la promesa del doble matrimonio entre don Fernando y Margarita por un lado, y de Arlaxa y Alimuzel, por el otro. Sin embargo, Cervantes se cuida muy ingeniosamente de dar una solución al conflicto sobre la gallardía (y la fe religiosa) de don Fernando. El epíteto épico que constituye el título es deconstruido por las acciones y palabras de los personajes, y devaluado al aplicarse a muchos otros personajes aparte de Saavedra. Esto, unido al hecho apuntado por Kartchner de que don Fernando nunca llega a descifrar sus motivaciones en la «diegesis dramática», deja nuestro deseo de comprobar su gallardía, como el de la propia Arlaxa, completamente insatisfecho. Sin final, sin márgenes que lo delimiten, la búsqueda de la verdad sobre el conflicto conduce irremediablemente al lector/espectador a la aporia o impasse derrideano.

\section{OBRAS CITADAS}

ABEL, LIONEL, Metatheatre: A New View of Dramatic Form. New York, Hill and Wang, 1963.

Alter, Robert, Partial Magic: The Novel as a Self-Conscious Genre. Berkeley, CA, University of California Press, 1975.

ARboleda, CARlos ARTURo, Teoría y formas del metateatro en Cervantes. Salamanca, Universidad de Salamanca, 1991.

CASA, Frank P., "Some Remarks on Professor O'Connor's Article "Is the Spanish Comedia a Metatheater?" ", Bulletin of the Comediantes, 28, 1976, 27-31.

Casalduero, Joaquín, Sentido y forma del teatro de Cervantes. Madrid, Gredos, 1966.

Cervantes, Miguel DE, Teatro completo. Barcelona, Planeta, 1987.

- El ingenioso hidalgo don Quijote de la Mancha. Madrid, Castalia, 1991.

ChaYTor, H. J., ed., Dramatic Theory in Spain: Extracts from Literature Before and During the Golden Age. London, Cambridge UP, 1925. 
DARBORD, Michel, "Cervantes et le Théâtre», M. T. JonEs-DAVIES, ed., Verité et illusion dans le Théâtre au temps de la Renaissance. Paris, Jean Touzot, 1983, 21-25.

De ARMAS, FredericK A., "Los excesos de Venus y Marte en El gallardo español», Cervantes, su obra y su mundo: Actas del I Congreso Internacional sobre Cervantes. Ed. Manuel Criado de Val. Madrid, Edi-6, 1981, 249-59.

DERRIDA, JACQUES, Aporias. Trad. por Thomas Dutoit. Stanford, CA, Stanford UP, 1993.

FRIEDMAN, EDWARD H., The Unifying Concept: Approaches to the Structure of Cervantes' Comedias. York, SC, Spanish Literature Publications Company, 1981.

Gerl, E. Michael, "Aristotle in Africa: History, Fiction, and Truth in El gallardo español», Cervantes, 15:2, 1995, 43-57.

Guillén, Claudio, Literature as System: Essays Toward the Theory of Literary History. Princeton, N.J., Princeton UP, 1971.

HoRnBy, RICHARD, Drama, Metadrama, and Perception. Cranbury, NJ, Associated University Presses, 1986.

KARTCHNER, ERIC J., "Dramatic Diegesis: Truth and Fiction in Cervantes's El gallardo español", Yearbook of Comparative and General Literature, 47, 1999, 25-35.

Kenworthy, PATRICIA, "La ilusión dramática en los Entremeses de Cervantes», Cervantes, su obra y su mundo: Actas del I Congreso Internacional sobre Cervantes. Ed. Manuel Criado de Val. Madrid, Edi-6, 1981, 235-38.

Larson, Catherine, "Metatheater and the Comedia: Past, Present, and Future», The Golden Age Comedia. Text, Theory, and Performance. Eds. Charles Ganelin y Howard Mancing. West Lafayette, IN, Purdue UP, 1994, 204-21.

LIPMANN, STEPHEN, "Metatheater' and the Criticism of the Comedia», Modern Language Notes, 91, 1976, 231-46.

Newels, Margarete, Los géneros dramáticos en las poéticas del Siglo de Oro. Trad. Amadeo Sole-Leris. London, Tamesis Books, 1974.

O'CONNOR, THOMAS A., "Is the Spanish Comedia a Metatheater?», Hispanic Review, 43, 1975, 275-89.

- «Metatheater and the Comedia: A Further Comment», Modern Language Notes, 92, 1977, 336-38.

- «La vida es sueño: A View from Metatheater», Kentucky Romance Quarterly, 25, 1978, 13-26.

ozco DíAz, EmILIo, El teatro y la teatralidad del Barroco. Barcelona, Planeta, 1969.

v, EDWARD C., Teoría de la novela en Cervantes. Madrid, Taurus, 1966.

ROSA, "El retablo de las maravillas come testo metateatrale», Symbolae nae II. Eds. Blanca Periñán y Francesco Guazzelli. Pisa, Giardini Editori, 515-25.

IRROYO, Florencio, y ANTONIO Rey HaZAS, eds., Teatro completo de MiCervantes. Barcelona, Planeta, 1987.

'N L., "Cervantes and His Audience: Aspects of Reception Theory in El - de las maravillas», The Golden Age Comedia: Text, Theory, and Performanc. Eds. Charles Ganelin y Howard Mancing. West Lafayette, IN, Purdue UP, 1994, 249-61.

SONTAG, SUSAN, "The Death of Tragedy», Against Interpretation, and Other Essays. New York, Farrar, Straus \& Giroux, 1966, 132-39.

STAPP, William A., "El Gallardo español: la fama como arbitrio de la realidad", Manuel Criado de Val, ed., Cervantes, su obra y su mundo: Actas del I Congreso Internacional sobre Cervantes. Madrid, Edi-6, 1981, 261-72.

TODOROv, TzveTan, Introducción a la literatura fantástica. Trad. Silvia Delpy. México, D.F., Premia Editora, 1981. 
Valbuena Prat, Ángel, El teatro español en su Siglo de Oro. Barcelona, Planeta, 1969.

WeIMER, Christopher B., "Going to Extremes: Barthes, Lacan, and Cervantes' La gran sultana». Gender, Identity, and Representation in Spain's Golden Age. Eds. Anita K. Stoll y Dawn L. Smith. London, Associated University Presses, 2000, 47-60. 